\title{
Inducible variation in hypoxia tolerance across the intertidal-subtidal distribution of the blue mussel Mytilus edulis
}

\author{
Andrew H. Altieri* \\ Department of Ecology and Evolutionary Biology, Brown University, Providence, Rhode Island 02912, USA \\ Present address: Marine Science Center, Northeastern University, 430 Nahant Road, Nahant, Massachusetts 01908, USA
}

\begin{abstract}
The distribution of the blue mussel Mytilus edulis spans a steep gradient of environmental stress between intertidal and subtidal habitats, and can provide insight into population-scale patterns and underlying processes of variation in physiological tolerances. I conducted a 7 wk reciprocal transplant of mussels between the upper intertidal and subtidal portion of their natural depth distribution, and then assayed their tolerance to either aerial exposure or submerged hypoxia in the laboratory. Intertidal mussels transplanted back to the intertidal had a tolerance to aerial exposure $50 \%$ higher than subtidal mussels that remained in the subtidal. That difference can be explained by changes in mussel physiology induced by ambient conditions, since the tolerance of mussels transplanted between the intertidal and subtidal became similar to mussels occurring naturally in each habitat. The tolerance of mussels to submergence in hypoxic water-an environmental stress exacerbated by anthropogenic factors that experimental mussels had not encountered in the field followed a pattern qualitatively similar to the aerial exposure assay: intertidal mussels had higher survivorship in hypoxic water than those from the subtidal, and an elevated tolerance was induced by transplanting subtidal individuals to the intertidal. These results suggest that the response of mussels to a change in environmental conditions could vary between the center and edge of their depth distribution as a function of stress previously encountered.
\end{abstract}

KEY WORDS: Environmental stress $\cdot$ Dissolved oxygen $\cdot$ Foundation species $\cdot$ Hypoxia $\cdot$ Intertidal $\cdot$ Mytilus edulis $\cdot$ Narragansett Bay $\cdot$ Physiology $\cdot$ Stress gradient $\cdot$ Subtidal

\section{INTRODUCTION}

Understanding the characteristics of species at the boundary of their distributions is a fundamental pursuit of ecology. The intertidal zone is a model system for studying limiting factors, since the ocean margin marks a range limit for many terrestrial and marine organisms (Holt \& Keitt 2005). Physiological stresses associated with aerial exposure, including desiccation, temperature, ultraviolet radiation, and low-oxygen (hypoxia), can limit the upper boundary of many intertidal species, and the vertical zonation pattern characteristic of the intertidal organisms reflects variation in stress tolerance among species (Stephenson \& Stephenson 1949). Considerable variation in tolerance along the intertidal stress gradient can exist within a species as well. That variation can be produced by either post-settlement mortality that selects for genotypes with higher tolerance (Schmidt et al. 2000), or by inducible physiological responses (Halpin et al. 2004). Inducible responses are of particular interest since they can reveal fitness costs associated with stress tolerance (Lively 1986) and aid our ability to predict responses to a changing environment at organismal, population, and species levels of ecological organisation. 
Hypoxic stress during emersion (due to inefficiency of gas exchange and isolation of body tissues for water conservation) can induce a physiological response within intertidal organisms and limit their distribution (Brinkhoff et al. 1983, Branch et al. 1988, Shick et al. 1988). Mytilus edulis is an ideal species with which to examine inducible responses to hypoxic stress associated with aerial exposure because their distribution spans a steep stress gradient from the mid-intertidal, where aerial exposure is encountered daily, to the subtidal, where aerial exposure is never encountered. Studies that compared subtidally cultured mussels with wild intertidal mussels from a different site revealed that intertidal mussels had a higher tolerance for aerial exposure than those from the subtidal, and that cultured mussels acclimated to intertidal conditions could acquire a higher tolerance (Wijsman 1976, Demers \& Guderley 1994, Guderley et al. 1994, Sukhotin \& Portner 1999). However, it remains to be examined whether differences in hypoxic tolerance exist between subtidal and intertidal portions of a natural mussel population and whether higher hypoxia tolerance in intertidal mussels is both gained and lost when mussels are reciprocally transplanted between the subtidal and intertidal.

The physiological mechanisms that determine the distribution and success of Mytilus edulis are of considerable interest - mussels are a prey resource, foundation species, and dominant competitor (see Seed \& Suchanek 1992 for review), and so other species are secondarily dependent on their response to stress. Moreover, identifying population-level variation in tolerance to low oxygen is of enormous practical importance since the prevalence of water-column hypoxia is rapidly increasing due to anthropogenic activities and is currently among the severest forms of habitat degradation in coastal waters worldwide (Diaz 2001, UNEP 2004). Increased ability for anaerobiosis induced by aerial exposure should lead to greater tolerance for submergence in hypoxic water as well. This study was conducted in Narragansett Bay, Rhode Island, USA, where mussels create essential habitat that structures the distribution of associated infauna (Lindsey et al. 2006). Severe eutrophication in Narragansett Bay generates periods of water-column hypoxia which can lead to local extinction of the mussels and loss of their ecological functions (Altieri \& Witman 2006).

The purpose of this study was to: (1) quantify variation in tolerance to aerial exposure within a population of mussels that spans the subtidal and intertidal stress gradient, (2) examine whether that variation in tolerance is an inducible response that is gained in the intertidal and lost in the subtidal, and (3) determine if an induced response to one stress (aerial exposure) will confer higher tolerance to a related but different stress (submergence in hypoxic water).

\section{MATERIALS AND METHODS}

I examined the stress tolerance of Mytilus edulis from the intertidal and subtidal by conducting a 2stage experiment. The first stage consisted of a field experiment in which mussels were reciprocally transplanted between the intertidal and subtidal to allow for an inducible stress response. The second stage consisted of a laboratory survivorship-assay to test the stress tolerance of mussels from the field experiment. To isolate the hypoxic effects of aerial exposure from temperature, the study was conducted in the mild fall season (3 October to 21 November 2003), when both air and water temperatures were similar and remained below $22^{\circ} \mathrm{C}$ (mean $\pm 1 \mathrm{SE}$ : intertidal: $11.7 \pm 0.05^{\circ} \mathrm{C}$; subtidal: $13.3 \pm 0.03^{\circ} \mathrm{C}$ ). Air and water temperatures experienced by the mussels were monitored with Onset Hobo temperature loggers throughout the field experiment, transport to the laboratory, and the laboratory-survivorship assay. The concentration of dissolved oxygen in surface waters was monitored by data logging sondes (Yellow Springs Instruments No. 6600).

The field transplant experiment was conducted on pilings of the 'T-wharf' pier in the Narragansett Bay National Estuarine Research Reserve on Prudence Island, Rhode Island, USA $\left(41^{\circ} 34^{\prime} \mathrm{N}, 71^{\circ} 19^{\prime} \mathrm{W}\right)$. The pilings were chosen because they offered a vertical substrate in protected waters, which minimized the splash and wave run-up that can confound tidal elevation on naturally sloping intertidal areas. In addition to predictable emersion time, the vertical substrate created a minimal distance between intertidal and subtidal heights. The wooden pilings were installed during World War II-era construction of the wharf, and are presently inhabited by a faunal community typical of nearby rocky areas (i.e. encrusted by barnacles, mussels, bryozoans, sponges, and ascidians, and visited by seastars, crabs, and snails). Mussels (2.5 to $3.5 \mathrm{~cm}$ length) were reciprocally transplanted for a $7 \mathrm{wk}$ period (including control transplants back to the same tidal height) between the intertidal and subtidal portions of their range ( +0.9 and -1.5 m mean lower low water, respectively) in $20 \times 10 \times 5 \mathrm{~cm}$ (length $\times$ width $\times$ height) plastic-mesh pouches $(7 \mathrm{~mm}$ mesh size) fixed to pilings with cable ties (Fig. 1); 30 mussels from a given tidal height were placed in each mesh pouch, with 24 replicate pouches for each of the 4 transplant treatments. At the conclusion of the field experiment, the pouches were retrieved, transferred to the laboratory in aerated seawater, and mussels were scored for survivorship through the transplant period.

For the laboratory survivorship assay, 20 mussels from each transplant pouch were placed in a chamber with 1 of 3 assay treatments: open air (to simulate aerial exposure at low tide), seawater bubbled with air (submersion under normoxic conditions $>5.0 \mathrm{mg} \mathrm{l}^{-1}$ dis- 
solved oxygen), and seawater bubbled with nitrogen (submersion in hypoxic conditions of $0.5 \mathrm{mg} \mathrm{l}^{-1}$ dissolved oxygen - a level of hypoxia observed in some areas of Narragansett Bay; A. Altieri unpubl. data). There were 8 replicate chambers for each of the 12 treatment combinations (4 field treatments $\times 3$ laboratory assay treatments; Fig. 1). Seawater (30\%) was made from Crystal Sea Marinemix (Marine Enterprises International) to ensure consistent water quality throughout the experiment. Chambers were cylindrical $(11.5 \times 9.5 \mathrm{~cm}$, diameter $\times$ height $)$ and made of translucent plastic. In open-air treatments, chambers were lined with a damp cloth to maintain high humidity. To minimize evaporative changes to salinity in the other 2 treatments, air and nitrogen were humidified before entering chambers by first bubbling the gases through bottles containing de-ionized water. Water in chambers was changed every $24 \mathrm{~h}$. Chambers were maintained at a constant temperature of $22^{\circ} \mathrm{C}$ and a photocycle of $14 \mathrm{~h}$ light:10 h dark. Every $12 \mathrm{~h}$, dead mussels (both gaping and unresponsive to tactile stimulus) were removed from each chamber, and the number of live mussels remaining was recorded. All mussels in submerged treatments were observed to have shells open and softtissue exposed, whereas some live mussels exposed to air were gaping and others kept their valves closed.

Analysis of variance (ANOVA) was used to test for field-transplant and laboratory-assay treatment effects on mussel survivorship. The proportion of mussels

Tidal range $(\mathrm{m})$

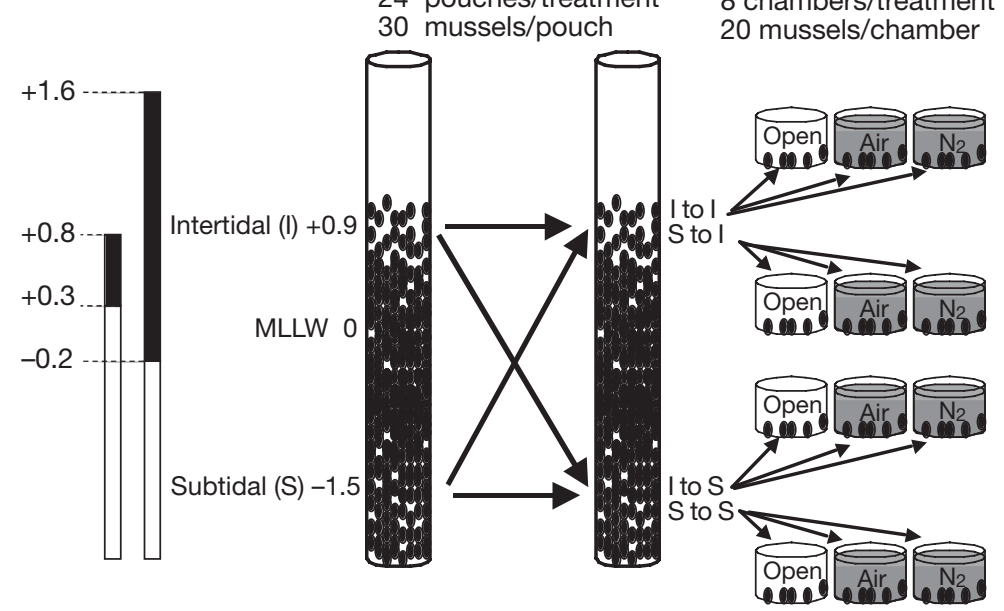

Fig. 1. Diagram of experimental design. Tall cylinders represent pier pilings on which the reciprocal transplant was conducted, and are to scale with the height of shaded portion of bars at left, which represent maximum (right shaded bar) and minimum (left shaded bar) tidal amplitude during the transplant experiment. Squat cylinders represent chambers from the laboratory assay with 3 treatments (Open: open air to simulate aerial exposure at low tide; Air: seawater bubbled with air to simulate submersion under normoxic conditions; $\mathrm{N}_{2}$ : seawater bubbled with nitrogen to simulate submersion in hypoxic conditions; black ovals: mussels; MLLW: mean lower low water) surviving in replicate pouches at the end of the field transplant was arcsine, square-root transformed to meet assumptions of normality, and analyzed with transplant treatment (intertidal to intertidal, subtidal to intertidal, etc.) as a fixed factor in a 1-way ANOVA. The survivorship response in the laboratory assay was the time to mortality of $50 \%$ of the mussels in each replicate chamber, as calculated by Kaplan-Meier survivorship analysis. Differences in time to $50 \%$ mortality were analyzed as a separate ANOVA for each laboratory- assay treatment (i.e. aerial exposure, submerged hypoxia, submerged anoxia), with transplant treatment as a fixed factor in a 1-way ANOVA. ost hoc, pair-wise analyses were carried out by Tey's test of honestly significant differences. All v5.0 (SAS Institute).

\section{RESULTS}

In the field experiment, $>99 \pm 0 \%$ (mean $\pm \mathrm{SE}$ ) of mussels in all treatments survived the transplant period, and there was no difference among treatments $\left(F_{3,92}=1.50, \mathrm{p}=0.22\right)$. The laboratory assay revealed that intertidal mussels had a higher tolerance than subtidal mussels to both aerial exposure $\left(F_{3,28}=16.46\right.$, $\mathrm{p}<0.0001)$ and aqueous hypoxia $\left(F_{3,28}=13.20, \mathrm{p}<\right.$ $0.0001)$, regardless of whether they were originally from the intertidal or transplanted there from the subtidal (Figs. 2 \& 3), indicating that an inducible tolerance to low-oxygen environments was gained in the stressful intertidal. Moreover, the higher tolerance among intertidal mussels to aerial exposure was lost when they were transplanted to the subtidal, and a similar, though insignificant, trend towards loss of aqueous hypoxia tolerance was observed (Fig. 3). Survivorship in seawater bubbled with air was $>97 \pm 0 \%$ (mean $\pm \mathrm{SE}$ ) for all transplant treatments through the end of the experiment, and there was no difference among field transplant treatments $\left(F_{3,28}=2.81, \mathrm{p}>0.05\right)$.

\section{DISCUSSION}

The tolerance of Mytilus edulis to aerial exposure varied along the intertidalsubtidal gradient. The average survival rate of intertidal mussels in sustained aerial exposure was $50 \%$ higher than that of subtidal mussels. The reciprocal trans- 


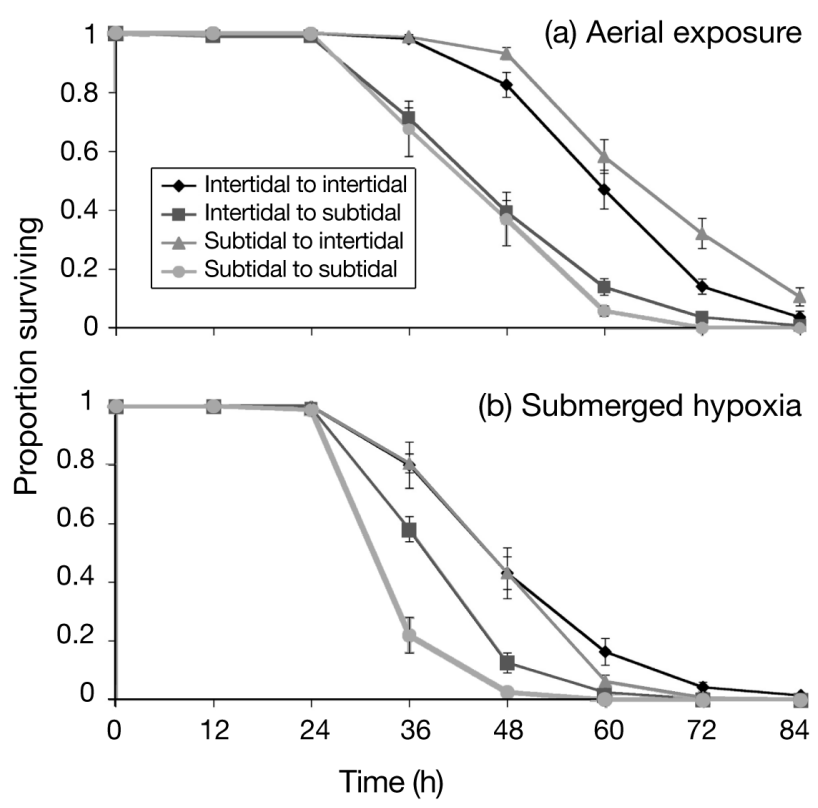

Fig. 2. Survivorship curves from the laboratory assay, which tested the tolerance of transplanted mussels to: (a) open air (to simulate aerial exposure at low tide) and (b) water bubbled with nitrogen (submersion in hypoxic conditions). Points: means of proportion surviving at each time point in 8 replicate chambers $( \pm 1 \mathrm{SE})$

plant of mussels between the intertidal and subtidal revealed that higher tolerance to aerial exposure was an inducible response that was gained or lost depending on whether mussels had acclimated to intertidal or subtidal conditions (respectively) prior to the laboratory assay. More than $99 \%$ of all mussels survived the transplant experiment, indicating that: (1) nearly all individuals were able to adjust their physiology to cope with environmental conditions from across the depth range of the population and (2) selective mortality was not responsible for differences in survivorship subsequently detected in the laboratory-survivorship assay. Induced tolerance to hypoxic conditions associated with aerial exposure in the intertidal conferred higher tolerance to the related stress of submersion in hypoxic water.

The tolerance to hypoxic conditions was both gained in the stressful intertidal and lost in the relatively benign conditions of the subtidal, which suggests there is a cost associated with maintenance of the physiological mechanism that aids survival during aerial exposure (Levins 1968, Lively 1986, Harvell 1990). All mussels undergo a rapid metabolic transition within hours of aerial exposure, including the depression of metabolic rate and a switch to anaerobic pathways (de Zwaan \& Wijsman 1976, Widdows et al. 1979, Shick et al. 1983). There are additional changes induced by long-term (weeks) cyclic exposure to air (i.e. tidal

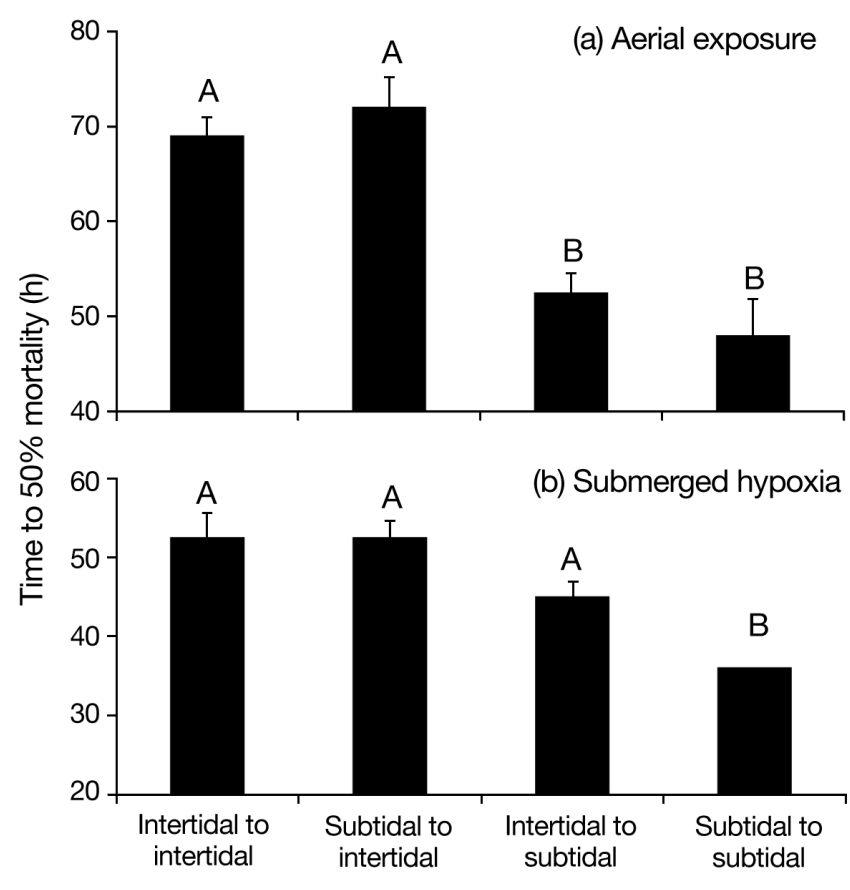

Fig. 3. Median survivorship (time to $50 \%$ mortality of mussels in each chamber) in the laboratory assay that tested the tolerance of transplanted mussels to: (a) open air (to simulate aerial exposure at low tide) and (b) water bubbled with nitrogen (submersion in hypoxic conditions). Bars: means of median survivorship (calculated by Kaplan-Meier analysis) for 8 replicate chambers $(+1 \mathrm{SE})$. Bars with different letters are significantly different

cycles), including switches to alternative anaerobic pathways, regulation of key metabolic enzymes (e.g. pyruvate kinase), lowered baseline metabolic rate, and possibly higher mitochondria content (de Zwaan \& Wijsman 1976, Widdows \& Shick 1985, Shick et al. 1988, Demers \& Guderley 1994, Sukhotin \& Portner 1999). The latter set of induced changes explains the higher survivorship of intertidal mussels compared to subtidal mussels (whether naturally from the intertidal or transplanted there) in both aerial exposure and submerged hypoxia treatments. Additionally, mussels acclimated to the intertidal are able to utilize atmospheric oxygen during acute aerial exposure to a far greater extent than subtidal mussels, though it should be noted that mussels are still largely anaerobic in such instances and so aerial exposure still represents a hypoxic environment (Famme et al. 1981, Brinkhoff et al. 1983, Widdows \& Shick 1985, Shick et al. 1988). Laboratory studies in which aerial exposure and food ration were manipulated independently have revealed that modified rates of oxygen consumption (a product of conservation mechanisms outlined above) are due to the direct effects of aerial exposure, rather than the intermittent opportunity for feeding associated with 
cyclic tidal emersion (Widdows \& Shick 1985, Shick et al. 1988). Clearly, the history of exposure to hypoxic stress is a significant factor in the tolerance level of an individual. The physiological changes induced by aerial exposure, as revealed by studies in the laboratory and with cultured mussels, explain the patterns observed in this field study of a natural population.

Recognition of anthropogenic environmental change has increased interest in how related stresses acting at different scales can interact to determine the distribution of ecologically important species (Helmuth 1999, Harley 2003). The 2 stresses examined in this study occur across gradients of different scales: exposure to air, which occurs daily and varies at a scale of meters between the intertidal and subtidal, and submergence in hypoxic water, which can occur seasonally along a kilometer-scale estuarine gradient (Altieri \& Witman 2006). Variation in hypoxia tolerance within a mussel population that spans the intertidal-subtidal gradient could mediate the effects of seasonal water-column hypoxia. In areas of Narragansett Bay, where low oxygen conditions can persist for days or weeks and span the entire water column (RIDEM 2003, Bergondo et al. 2005), mussels in the intertidal that are acclimated to the cyclic hypoxic conditions associated with aerial exposure would be predicted to have higher survivorship than sub-tidal mussels during an acute episode of water-column hypoxia. When considering the response of a given species to environmental stress, it is necessary to take into account that tolerances may differ between the edge and center of a species distribution and that individuals are affected by past exposure to related stresses. This broad perspective on stress tolerance is necessary to predict the response of a species to a changing environment.

Acknowledgements. E. Lindsey was instrumental in both field and laboratory efforts, and M. Carrel assisted with portions of the laboratory work. The staff of the Narragansett Bay National Estuarine Research Reserve (NERR) made their pier facility and oceanographic data available. M. Tatar provided guidance on survivorship analyses. Comments by M. Brandt, L. Burnett, J. Palardy, C. Peterson, J. Witman, and 2 anonymous reviewers improved this manuscript. Rhode Island Sea Grant, a Partnership for Narragansett Bay Watershed Action Grant (US EPA) a NOAA NERRS Graduate Research Fellowship, and a Luce Environmental Fellowship provided funding for this study.

\section{LITERATURE CITED}

Altieri AH, Witman JD (2006) Local extinction of a foundation species in a hypoxic estuary: integrating individuals to ecosystem. Ecology 87:717-730

Bergondo DL, Kester DR, Stoffel HE, Woods WL (2005) Timeseries observations during the low sub-surface oxygen events in Narragansett Bay during summer 2001. Mar Chem 97:90-103
Branch GM, Borchers P, Brown CR, Didonnelly (1988) Temperature and food as factors influencing oxygen consumption of intertidal organisms, particularly limpets. Am Zool 28:137-146

Brinkhoff W, Stockmann K, Grieshaber M (1983) Natural occurrence of anaerobiosis in mollusks from intertidal habitats. Oecologia 57:151-155

Demers A, Guderley H (1994) Acclimatization to intertidal conditions modifies the physiological response to prolonged air exposure in Mytilus edulis. Mar Biol 118: $115-122$

de Zwaan A, Wijsman TCM (1976) Anaerobic metabolism in Bivalvia (Mollusca). Characteristics of anaerobic metabolism. Comp Biochem Physiol B 54:313-324

Diaz RJ (2001) Overview of hypoxia around the world. J Environ Qual 30:275-281

Famme P, Knudsen J, Hansen ES (1981) The effect of oxygen on the aerobic-anaerobic metabolism of the marine bivalve, Mytilus edulis L. Mar Biol Lett 2:345-351

Guderley H, Demers A, Couture P (1994) Acclimatization of blue mussel (Mytilus edulis Linnaeus, 1758) to intertidal conditions-Effects on mortality and gaping during air exposure. J Shellfish Res 13:379-385

Halpin PM, Menge BA, Hofmann GE (2004) Experimental demonstration of plasticity in the heat shock response of the intertidal mussel Mytilus californianus. Mar Ecol Prog Ser 276:137-145

Harley CDG (2003) Abiotic stress and herbivory interact to set range limits across a two-dimensional stress gradient. Ecology 84:1477-1488

Harvell CD (1990) The ecology and evolution of inducible defenses. Q Rev Biol 65:323-340

Helmuth B (1999) Thermal biology of rocky intertidal mussels: quantifying body temperatures using climatological data. Ecology 80:15-34

Holt RD, Keitt TH (2005) Species' borders: a unifying theme in ecology. Oikos 108:3-6

Levins R (1968) Evolution in changing environments. Princeton University Press, Princeton, NJ

Lindsey E, Altieri AH, Witman JD (2006) Influence of biogenic habitat on the recruitment and distribution of a subtidal xanthid crab. Mar Ecol Prog Ser 306:223-231

Lively CM (1986) Canalization versus developmental conversion in a spatially variable environment. Am Nat 128: 561-572

RIDEM (Rhode Island Department of Environmental Management) (2003) Greenwich Bay fish kill: causes, impacts and responses. RIDEM, Providence, RI. Available at: www.dem.ri.gov/pubs/fishkill.pdf

Schmidt PS, Bertness MD, Rand DM (2000) Environmental heterogeneity and balancing selection in the acorn barnacle Semibalanus balanoides. Proc R Soc Lond B 267: 379-384

Seed R, Suchanek TH (1992) Population and community ecology of Mytilus. In: Gosling E (ed) The mussel Mytilus edulis: ecology, physiology, genetics and culture. Elsevier, Amsterdam, p 87-169

Shick JM, de Zwaan A, Debont AMT (1983) Anoxic metabolic rate in the mussel Mytilus edulis L. estimated by simultaneous direct calorimetry and biochemical analysis. Physiol Zool 56:56-63

Shick JM, Widdows J, Gnaiger E (1988) Calorimetric studies of behavior, metabolism and energetics of sessile intertidal animals. Am Zool 28:161-181

Stephenson TA, Stephenson A (1949) The universal feature of zonation between tidemarks on rocky shores. J Ecol 38: 289-305 
Sukhotin AA, Portner HO (1999) Habitat as a factor involved in the physiological response to environmental anaerobiosis of White Sea Mytilus edulis. Mar Ecol Prog Ser 184: 149-160

UNEP (United Nations Environment Programme) (2004) Global environmental outlook (GEO): Year Book 2003. UNEP, London

Widdows J, Shick JM (1985) Physiological responses of

Editorial responsibility: Charles Peterson (Contributing Editor), Morehead City, North Carolina, USA
Mytilus edulis and Cardium edule to aerial exposure. Mar Biol 85:217-232

Widdows J, Bayne BL, Livingstone DR, Newell RIE, Donkin P (1979) Physiological and biochemical responses of bivalve mollusks to exposure to air. Comp Biochem Physiol A 62:301-308

Wijsman TCM (1976) ATP content and mortality in Mytilus edulis from different habitats in relation to anaerobiosis. Neth J Sea Res 10:140-148

Submitted: November 6, 2005; Accepted: April 27, 2006

Proofs received from author(s): October 6, 2006 